\title{
Influence of Maize Genotypes on Wheat Haploid Embryos Production in Maize Mediated Cross System
}

\author{
Ding Mingliang', Abdelkhalik Sedhom ${ }^{1,2 *}$, Li Hongsheng ${ }^{1}$, Yang \\ Mujun', Li Shaoxiang', Gu Jian', Zhao Hong1, Asim Mohamed', \\ Liu Kun ${ }^{1 *}$ \\ ${ }^{1}$ Institute of Food Crops, Yunnan Academy of Agricultural Sciences, \\ Kunming, China, ${ }^{2}$ Field Crops Research Institute, Agricultural Research \\ Center, Egypt
}

\begin{abstract}
QIX selected bread wheat double haploid genotypes with same heading time and different genetic background and eight maize genotypes belonging to four maize types (waxy, sweet waxy, sweet and super sweet maize types) were used in this study. The six wheat genotypes pollinated with the eight maize genotypes to produce wheat haploid embryos. The objective of this investigation was to study the effects of different maize genotypes of distinct types on the wheat haploid embryo ratio. The results showed that the same wheat material when pollinated with different maize genotype, the embryo rate differed between 1.5 to 3 times and ranging from $15.43 \%$ to $47.80 \%$. Screening high induction rate maize varieties was essential to improve the efficiency of wheat haploid production. The average haploid embryo induction rate among the four maize types was highest in sweet type (33.24\%) and lowest in super sweet type (29.59\%). The wheat genotype A6 recorded the highest embryo rate percentage $(34.11 \%)$, while A5 recorded the lowest rate (29.36\%). Baitiannuo SQW-1 (B4) found to be the highest for embryo rate, followed by the Yuntianyu 6 (B5) and Zhenhenuo 1(B1), while the lowest was recorded by Yunchaotian 2 (B8) genotype. The maize genotypes in the same type differed significantly regarding the haploid embryo induction rate of wheat genotypes and thus maize types were not consistent in their behavior. So, the key was to select maize genotypes with high induction rate for wheat haploids and not the maize type. The interaction between wheat genotype and maize genotype has a significant effect on the embryogenesis rate. Therefore, if the rate of embryo induction of some wheat materials with a common maize variety is low, it may be possible using the pollination of other maize genotypes to increase the embryogenesis in wheat $\mathrm{x}$ maize hybridization.
\end{abstract}

Key words: Wheat $\mathrm{x}$ maize hybridization, Maize genotypes, Embryo rate

\section{Introduction}

The establishment of maize pollen induced haploid technology has the characteristics of simple operation, low cost, good induction effect, etc. (Zenkteler and Nitzsche, 1984, Laurie and Bennett, 1986 and 1988). Wheat $\times$ maize hybridization is one of the most efficient methods for producing haploid in wheat, which can be used to accelerate germplasm innovation, multi-gene polymerization breeding, molecular mapping group and gene expression and function research, ...etc. (Laurie \& Reymondie,

1991, Chen \& Chen 1998, Li \& Dai 2000; Wang \& Zhang 2001, Gu \& Yang, 2002, Maluszynski et al., 2003, Gu et al., 2005 and 2006, Hussain et al., 2012, Ferrie, 2017 and Wiśniewska et al., 2019).

It is the precondition and basis for improving the haploid production efficiency of wheat to improve and stabilize the haploid embryo rate in

"Corresponding author: sedhom_aiad@yahoo.com 
the wheat haploid production of hybrid wheat $\mathrm{x}$ maize hybridization. Domestic and international studies show that the embryo rate of haploid embryo in wheat is influenced not only by the genotype of wheat material itself (Sun et al. , 1992, Inagaki \& Tahir, 1992, Kisan, 1993, Chen et al., 1996, Lefebvre \& Devaux, 1996, Inagaki, 1997, Chen et al., 1998, Christina et al., 1998, Wang, 1998, Vinesh et al., 1999, Cherkaout et al., 2000, Maluszynski et al., 2003, Cai et al., 2004, Cai et al., 2005a, Cai et al, 2006; Zhang et al. 2007; Zhang 2010 and Hussain et al., 2012), but also related to many factors, including maize genotype (Sun et al., 1992, Lefebvre and Devaux, 1996, Inagaki, 1997, Christina et al., 1998, Wang, 1998, Vinesh et al., 1999, Maluszynski et al., 2003 and Cai et al., 2005a), pollination (Chen et al., 1998 and $\mathrm{Gu}$ et al. 2006), 2,4-d treatment methods (Wang, 1998 and Cherkaout et al., 2000, Ballesteros et al., 2003, Maluszynski et al., 2003, Cai et al., 2004 and Cai et al., 2005), the treatment methods of hybrid spike after pollination, culture conditions (Cherkaout et al., 2000, Ballesteros et al., 2003, Cai et al., 2005 and Gu et al., 2008), ...etc., the most influential is the maize genotype (Chen and Chen 1998, Cai et al., 2004 and Gu et al. 2006).

Many researchers around the world have done some research on different types of maize to screen the maize varieties with high embryo rate (Christina et al., 1998, Cai et al., 2005a,b and Gu et al., 2006). The result was different from one to other; some results showed that the haploid embryo induction rate of popcorn is the highest, while in some studies sweet corn or sweet waxy corn is best. Results were different may be because of the varying wheat materials used in these studies, that is $F_{1}$ and $F_{2}$ of the hybrid offspring and the gametes is different. On this basis, the selection of maize genotypes with high embryo yield potential for haploid embryo has become a research focus to improve the embryo yield of wheat. So, this study intends to use six wheat double haploid lines and eight different genotypes of maize belonging to four maize types. The objective of this investigation was to study the effects of different maize types and varieties on the yield of wheat haploid embryos.

\section{Materials and Methods}

During 2016 season in Yunnan Academy of Agricultural Sciences, Songming Scientific Research Experimental Station, six bread wheat genotypes were selected from 4100 double haploid lines. These six genotypes had the same heading time and different genetic background. For this study, these six genotypes were denoted as A1 to A6.

Four types of maize (waxy, sweet waxy, sweet and super sweet maize types) were used in this study. Eight maize genotypes (from B1 to B8) selected by the Institute of Agricultural Sciences of Yunnan Province from all types are listed in Table 1.

Wheat $x$ Maize hybridization experiment was conducted in the summer of 2017 in Kunming, Yunnan, China. Maize genotypes were sown at three sowing dates, determined according to $\mathrm{Gu}$ et al. (2006), with six days interval to ensure availability of sufficient pollen sources throughout the reproductive stage of the wheat genotypes. Wheat genotypes were planted in one sowing date because these genotypes had same heading time. At heading stage at least 48 spikes were selected from each wheat genotypes. The central floret of each spikelet was removed by forceps to produce more space for lateral florets. Wheat anthers were removed manually with the help of fine forceps and spikes were covered with paper bag to prevent cross pollination. After 24 hours of emasculation, fresh maize pollen from eight maize genotypes were collected in paper and pollinated emasculated spikes (Figure 1). Each treatment had six spikes dividing in three replications ( 2 spikes per repetition). The tillers with pollinated spikes were cut near the soil after 24 hour of pollination and kept in water. The cut spikes sprayed with $100 \mathrm{ppm}$ 2, 4-Dichlorophenoxyacetic acid (2, 4-D) and transferred to nutrition solution. All spikes put in growth chamber with the nutrition solution. After 13-14 days from cutting, spikes were separated for each treatment and green parthenocarpic caryopsis (GPC's) were removed from the florets.

Data were recorded for number of florets pollinated and number of GPCs Developed. Total numbers of haploid embryos were counted using a microscope. The embryo ratio percentage (also called "haploid embryo induction rate") was calculated as follow:

Embryo ratio $(\%)=$ Total number of haploid embryos/total number of florets pollinated x 100 . Data for embryo ratio was statistically analyzed using DPS (data processing software) via analysis of variance using complete randomized design. 
TABLE 1. Selected maize genotypes used in this study

\begin{tabular}{cl}
\hline Maize types & \multicolumn{1}{c}{ Maize genotypes } \\
\hline Waxy & B1 (Zhenhenuo 1) \\
& B2 (Yunnuo 3) \\
Sweet waxy & B3 (Tiannuo 888) \\
& B4 (Baitiannuo SQW-1) \\
Sweet & B5 (Yuntianyu 6) \\
& B6 (Zhenhetianyu 1) \\
Super sweet & B7 (Yunchaotian 1) \\
& B8 (Yunchaotian 2)
\end{tabular}

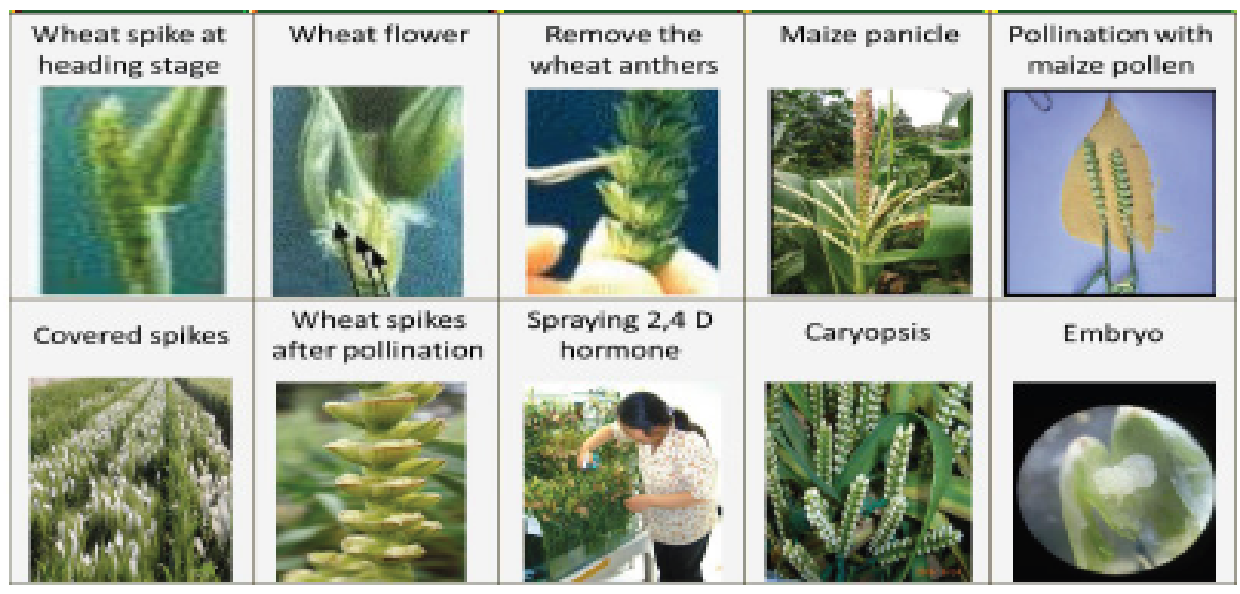

Fig. 1. Simple procedure for haploid embryos plant production by wheat $\mathbf{x}$ maize hybridization system

\section{Results and Discussion}

Analyses of variance

The analyses of variance (ANOVA) for embryo rate are presented in Table 2. The ANOVA revealed highly significant differences for wheat and maize genotypes. These results indicated that these genotypes were diverse and comparisons between genotypic means became valid. The highly significant differences for wheat $\mathrm{x}$ maize genotypic interactions indicated that wheat genotypes responded variably to the different maize genotypes suggesting the importance of assessing particular wheat genotype(s) for specific maize genotype in order to get high haploid embryo rate.

\section{Mean performance}

The average of wheat genotypes for number of florets pollinated, number of GPCs developed caryopsis, number of embryos and embryo rate $(\%)$ were illustrated in Table 3. Number of pollinated florets ranged from 1474 to 1787 for A3 and A6, respectively. A2 genotype recorded lowest values of number of GPCs and the number of embryos developed. A1 and A6 genotypes recorded the highest values of number of GPCs (1548) and number of developed embryos (525), respectively. According to the results of the average haploid embryogenesis rate of 6 wheat $\mathrm{DH}$ lines, embryo development rate ranged from $29.36 \%$ to $34.11 \%$. A6 and A3 recorded the highest embryogenesis rate $(34.11 \%$ and $33.36 \%$ respectively), while A5 recorded the lowest rate $(29.36 \%)$.

Eight maize genotypes were used to pollinate six wheat double haploid lines, and the average rate of embryo for 6 wheat DH Lines, induced by each maize genotype, is given in Table 4 . The data 
TABLE 2. Analyses of variance for the haploid embryo rate

\begin{tabular}{cccccc}
\hline SOV & df & SS & MS & F & p \\
\hline Wheat genotypes (A) & 5 & 213.2183 & 42.6437 & 53.306916 & $1 \mathrm{E}-07$ \\
Maize genotypes (B) & 7 & 852.6342 & 121.8049 & 152.26267 & $1 \mathrm{E}-07$ \\
$\mathrm{~A} \times \mathrm{B}$ & 35 & 3741.9320 & 106.9123 & 133.64612 & $1 \mathrm{E}-07$ \\
Error & 96 & 76.7967 & 0.79997 & & \\
\hline
\end{tabular}

TABLE 3. Mean values of florets pollinated, GPCs developed caryopsis, embryos developed and embryo rate (\%) for six wheat genotypes

\begin{tabular}{ccccc}
\hline $\begin{array}{c}\text { Wheat } \\
\text { genotypes }\end{array}$ & $\begin{array}{c}\text { Florets pollinated } \\
\text { (numbers) }\end{array}$ & $\begin{array}{c}\text { GPCs } \\
\text { Developed Caryopsis } \\
\text { (numbers) }\end{array}$ & $\begin{array}{c}\text { Embryos } \\
\text { Developed } \\
\text { (numbers) }\end{array}$ & $\begin{array}{c}\text { Embryogenesis } \\
\text { rate }(\%)\end{array}$ \\
\hline A1 & 1760 & 1548 & 494 & $31.91 \mathrm{c}$ \\
A2 & 1559 & 1241 & 405 & $32.63 \mathrm{bc}$ \\
A3 & 1474 & 1367 & 456 & $33.36 \mathrm{ab}$ \\
A4 & 1675 & 1268 & 409 & $32.26 \mathrm{c}$ \\
A5 & 1648 & 1410 & 414 & $29.36 \mathrm{~d}$ \\
A6 & 1787 & 1539 & 525 & $34.11 \mathrm{a}$ \\
\hline
\end{tabular}

TABLE 4. Mean values of florets pollinated, GPCs developed caryopsis, embryos developed and embryogenesis rate $(\%)$ for eight maize genotypes

\begin{tabular}{lcccc}
\hline \multicolumn{1}{c}{ Maize genotypes } & $\begin{array}{c}\text { Florets } \\
\text { pollinated } \\
\text { (numbers) }\end{array}$ & $\begin{array}{c}\text { GPCs } \\
\text { Developed } \\
\text { Caryopsis } \\
\text { (number) }\end{array}$ & $\begin{array}{c}\text { Embryos } \\
\text { Developed } \\
\text { (numbers) }\end{array}$ & $\begin{array}{c}\text { Embryogenesis } \\
\text { rate }(\%)\end{array}$ \\
\hline B1 (Zhenhenuo 1) & 1413 & 1201 & 408 & $33.97 \mathrm{~b}$ \\
B2 (Yunnuo 3) & 1098 & 892 & 290 & $32.51 \mathrm{c}$ \\
B3 (Tiannuo 888) & 1296 & 1073 & 317 & $29.54 \mathrm{de}$ \\
B4 (Baitiannuo SQW-1) & 1371 & 1205 & 460 & $38.17 \mathrm{a}$ \\
B5 (Yuntianyu 6) & 1205 & 1031 & 357 & $34.63 \mathrm{~b}$ \\
B6 (Zhenhetianyu 1) & 1192 & 982 & 297 & $30.24 \mathrm{~d}$ \\
B7 (Yunchaotian 1) & 1270 & 1054 & 322 & $30.55 \mathrm{~d}$ \\
B8 (Yunchaotian 2) & 1158 & 936 & 268 & $28.63 \mathrm{e}$ \\
\hline
\end{tabular}

J. Sus. Agric. Sci. 45, No. 1 (2019) 
showed that there were significant differences in the induction rate of wheat haploid embryos between different genotypes of maize. It ranged from 28.63 to $38.17 \%$, the difference was about 10\%. Baitiannuo SQW-1 (B4) was the highest, followed by Yuntianyu 6 (B5) and Zhenhenuo 1 (B1). The lowest value recorded by Yunchaotian 2 (B8) genotype. Among them, Baitiannuo SQW1(B4) was the promising maize genotype with higher haploid embryo induction rate.

At the same time, different maize genotypes in the same type had significant effect on the haploid embryo induction rate of wheat genotypes (Table 5). For example in sweet waxy type, B3 (Tiannuo 888) and B4 (Baitiannuo SQW-1) were significantly different $(29.54 \%$ and $38.17 \%)$. Also, same results for waxy, sweet and super sweet types were enunciated. Among the four maize types (waxy, sweet waxy, sweet and super sweet), the average haploid embryo induction rate was varied as Sweet Waxy $(33.86 \%)>$ Waxy $(33.24 \%)>$ Sweet $(32.43 \%)>$ Super Sweet (29.59\%). However, the difference between two genotypes of sweet waxy type was $8.63 \%$ and sweet type was $4.38 \%$ (Table 5). However, this difference within the waxy and super sweet types was less.

According to genotypes, the induction rate of haploid embryo was B4 (Sweet waxy) >B5 (sweet) >B1 (waxy) >B2 (waxy) >B7 (super sweet), B6 (sweet) >B3 (Sweet waxy), B8 (super sweet). Since, maize types are not regular in inducing haploid embryos, so the key was to select maize genotypes with high induction rate of wheat haploid not maize type.

For this selection, the results showed that the difference of haploid induction rate between different genotypes in the same maize type (such as sweet waxy and sweet) is greater than that of different maize types. The eight different maize genotypes were significantly different in the rate of haploid embryo induction. There is no regularity between the types, so the key to screening high embryo rate maize varieties is to select maize genotypes rather than maize type. The results were inconsistent with the results of several previous studies. Gu et al. (2006), showed that the induction rate of haploid embryo altered from sweet waxy corn, sweet maize, corn, and common maize. Cai et al. 2005b, studied embryo rate on different wheat $\mathrm{F}_{1}$ material and placed as sweet corn $(35.7 \%)>$ flour corn $(11.6 \%)$ and popcorn $(8.7 \%)>$ waxy corn $(7.3 \%)$, as well as popcorn $(9.9 \%)>$ waxy corn $(8.9 \%)>$ flour corn $(8.2 \%)>$ Sweet corn $(4.6 \%)$. Wang 1998 , from $\mathrm{F}_{2}$ wheat materials obtained the order as sweet corn $(8.71)$ and waxy maize $(6.54 \%)>$ flour corn (5.65); Zhang, et al. 2007 concluded that sweet corn $(2.99 \%)>$ waxy corn $(2.27 \%)>$ flour corn (2.08\%); Wang. et al. 2016 considered as popcorn $(9.59 \%)>$ Sweet corn $(4.82 \%)$ and waxy corn $(4.35 \%)$; The reasons for these differences was because most of the wheat materials used by researchers are cross-descendant materials and in the same material spikes and florets differed. In addition to that, during each of these studies often only one genotype of maize was selected.

TABLE 5. Comparison of haploid embryo induction rate between maize types and genotypes

\begin{tabular}{|c|c|c|c|c|}
\hline $\begin{array}{l}\text { Maize } \\
\text { types }\end{array}$ & Maize genotypes & $\begin{array}{c}\text { Embryogenesis } \\
\text { rate }(\%)\end{array}$ & $\begin{array}{c}\text { Type means } \\
(\%)\end{array}$ & $\begin{array}{c}\text { Variance within } \\
\text { type }(\%)\end{array}$ \\
\hline \multirow{3}{*}{ Waxy } & B1 (Zhenhenuo 1) & $33.97 \mathrm{~b}$ & \multirow{3}{*}{33.24} & \multirow{3}{*}{1.45} \\
\hline & & & & \\
\hline & B2 (Yunnuo 3) & $32.51 \mathrm{c}$ & & \\
\hline \multirow{2}{*}{$\begin{array}{l}\text { Sweet } \\
\text { waxy }\end{array}$} & B3 (Tiannuo 888) & $29.54 \mathrm{de}$ & \multirow{2}{*}{33.86} & \multirow{2}{*}{8.63} \\
\hline & B4 (Baitiannuo SQW-1) & $38.17 \mathrm{a}$ & & \\
\hline \multirow{3}{*}{ Sweet } & B5 (Yuntianyu 6) & $34.63 \mathrm{~b}$ & \multirow{3}{*}{32.43} & \multirow{3}{*}{4.38} \\
\hline & & & & \\
\hline & B6 (Zhenhetianyu 1) & $30.24 \mathrm{~d}$ & & \\
\hline \multirow{2}{*}{$\begin{array}{l}\text { Super } \\
\text { sweet }\end{array}$} & B7 (Yunchaotian 1) & $30.55 \mathrm{~d}$ & \multirow{2}{*}{29.59} & \multirow{2}{*}{1.92} \\
\hline & B8 (Yunchaotian 2) & $28.63 \mathrm{e}$ & & \\
\hline
\end{tabular}


According to ANOVA results (Table 2), the interaction between wheat genotypes and maize genotypes had a significant effect on embryogenesis rate. In this experiment, the same wheat genotype was pollinated by different maize genotypes and the embryogenesis rate was statistically different (Table 6). The embryo ratio in $\mathrm{A} 1$ ranged from 41.80 to 21.12 by $\mathrm{B} 3$ and B8, respectively. Yuntianyu 6 (B5) and Tiannuo 888 (B3) recorded the highest (41.43) and lowest (19.44) values of embryo ration in A2 genotypes, respectively. B1 recorded the highest value (42.31), while B6 recorded the lowest one (28.56) in A3 wheat genotypes. Baitiannuo SQW-1 (B4) maize genotype was the best one in over all mean and it recorded the highest values with A4 (42.40), A5 (42.88) and A6 (47.80). The lowest embryo rate values in A4, A5 and A6 recorded with B3 (23.19), B2 (17.14) and B8 (15.43), respectively. Therefore, for some wheat materials, if the rate of embryo induction with a common maize variety is low, it may be possible to increase the embryogenesis rate significantly by using the pollination of other maize genotypes.

In this study, by pollinating the same wheat material with different maize genotypes, the embryo rate differed between 1.5 to 3 times. This is in consistent with the previous research results [Gu et al. 2006; Christina et al. 1998; Cai et al. 2005; Wang 1998; Cai et al. 2005b], indicating that screening for the high embryo rate of maize genotypes to improve the production efficiency of wheat $\mathrm{x}$ maize hybrid wheat haploid is very important.

In addition, the relationship between wheat genotypes and maize genotypes in this study had a significant effect on the embryo rate, and also there were differences between "general combining ability" and "specific combining ability" among maize genotypes and wheat genotypes for the embryo development. So, not only by screening wheat genotypes we could get higher haploid embryo induction rate with maize genotype (such as B4 in this study), but also the low embryo induction rate of a wheat genotype could be significantly improved by pollinating with different maize genotypes. It provides a new way to improve the embryo yield in wheat $\mathrm{x}$ maize hybridization and resultantly haploid production efficiency.

\section{Conclusion}

It could be concluded that by pollinating the same wheat material with different maize genotypes, the embryo rate differed between 1.5 to 3 times indicating the important of maize genotypes screening to improve the production efficiency of wheat $x$ maize hybrid wheat haploid. The results showed that the difference of haploid induction rate between different genotypes in the same maize type (such as sweet waxy and sweet) is greater than that of different maize types, so the key to screening high embryo rate maize varieties is to select maize genotypes rather than maize type. Although, wheat genotypes could get higher haploid embryo induction rate with B4 maize cultivar, the low embryo induction rate of a wheat genotype could be significantly improved by pollinating with different maize genotypes. Nevertheless, more investigations and research studies are needed for more understanding of the other factors which influence on frequency of fertilization and embryo formation to increase the efficiency of double haploid technique.

TABLE 6. Embryo rate listed as maize genotype $x$ wheat genotype two-way data format

\begin{tabular}{ccccccc}
\hline Genotypes & A1 & A2 & A3 & A4 & A5 & A6 \\
\hline B1 & $28.88 \mathrm{~d}$ & $40.37 \mathrm{a}$ & $42.31 \mathrm{a}$ & $33.54 \mathrm{c}$ & $23.76 \mathrm{e}$ & $34.88 \mathrm{~d}$ \\
B2 & $33.63 \mathrm{c}$ & $33.63 \mathrm{~b}$ & $35.52 \mathrm{~b}$ & $30.87 \mathrm{~cd}$ & $17.14 \mathrm{f}$ & $44.27 \mathrm{~b}$ \\
B3 & $41.80 \mathrm{a}$ & $19.44 \mathrm{~d}$ & $30.27 \mathrm{de}$ & $23.19 \mathrm{f}$ & $28.97 \mathrm{~d}$ & $33.55 \mathrm{~d}$ \\
B4 & $30.22 \mathrm{~d}$ & $34.85 \mathrm{~b}$ & $30.89 \mathrm{de}$ & $42.40 \mathrm{a}$ & $42.88 \mathrm{a}$ & $47.80 \mathrm{a}$ \\
B5 & $34.03 \mathrm{c}$ & $41.43 \mathrm{a}$ & $34.63 \mathrm{bc}$ & $33.57 \mathrm{c}$ & $24.65 \mathrm{e}$ & $39.40 \mathrm{c}$ \\
B6 & $37.26 \mathrm{~b}$ & $35.95 \mathrm{~b}$ & $28.56 \mathrm{e}$ & $30.52 \mathrm{~d}$ & $26.24 \mathrm{de}$ & $22.92 \mathrm{e}$ \\
B7 & $28.33 \mathrm{~d}$ & $26.28 \mathrm{c}$ & $32.82 \mathrm{~cd}$ & $27.28 \mathrm{e}$ & $33.91 \mathrm{c}$ & $34.70 \mathrm{~d}$ \\
B8 & $21.12 \mathrm{e}$ & $29.09 \mathrm{c}$ & $31.95 \mathrm{~cd}$ & $36.83 \mathrm{~b}$ & $37.37 \mathrm{~b}$ & $15.43 \mathrm{f}$ \\
\hline
\end{tabular}




\section{References}

Ballesteros, J., Garcia, C., Ramirez, M. C. and Martin, A. (2003) Low relative humidity increase haploid production in durum wheat $\times$ maize crosses. Plant breeding, 122, 276-278.

Cai, H., Ma, C., Shi, H., and Lu, W. (2005a) Studies on wheat haploid induced by different wheat combinations and different maize genotype hybridization. Crop Journal, 3, 67-69.

Cai, H., Ma, C., Shi, H., and Lu, W. (2005b) Study on improving haploid embryo rate produced by wheat $\times$ maize. Journal of Triticeae Crops, 25 (6), 20-24.

Cai, H., Ma, C., Shi, H., Qiao, Y. and Lu, W. (2006) Research progress in the induction of wheat double haploid by distant hybridization between wheat and maize. Journal of Triticeae Crops, 26 (4), 154-157.

Cai, H., Ma, C., Zhou, W., Ma, H. and Lu, W. (2004) Study on wheat haploid induced by wheat and corn hybridization. Journal of Triticeae Crops, 24 (2), 11-14.

Chen, X. M. and Chen, X. A. (1998) Progress in the study of haploid and double haploid production in wheat $\times$ maize. Journal of Triticeae Crops, 18 (3), 1-4.

Chen, X., Lai, G., Chen, X., Zhou, J., Liu, J. and Sun, F. (1996) Differences in haploid production by different wheat combinations and maize hybrids. Acta Agronomica Sinica, 22 (4), 437-441.

Chen, X., Li, X., Chen, X., Meng, F. and Cui, S. (1998) Effects of different hybridization techniques on haploid production in wheat $\times$ maize. Acta Agronomica Sinica, 24 (6), 743-746.

Cherkaout, S., Lamsaouri, O., Chlyah, A. and Chlyah, H. (2000) Durnm wheat $\times$ maize crosses for haploid wheat production: influence of parental genotypes and various experimental factors. Plant Breeding, 119, 31-36.

Christina, B., Sabine, G. and Tamas, L. (1998) Effects of parental genotypes on haploid embryo and plantlet formation in wheat $\times$ maize crosses. Euphytica, 103, 319-323.

DPS software, Tang, Q. Y. and Zhang, C. X. (2013). Data Processing System (DPS) software with experimental design, statistical analysis and data mining developed for use in entomological research. Insect Science, 20 (2), 254-260.
Ferrie, A. M. R. (2017) Doubled Haploid production in higher plants. Encyclopedia of Applied Plant Sciences, 2, 147-151.

Gu, J. and Yang M. (2002) Study on fertility purification of thermo-sensitive genic male sterile lines in wheat. Journal of Triticeae Crops, 22 (2), 30-32.

Gu, J., Liu, W., Li, S., Tian, Y., Yang, H. and Yang, M. (2008) Study on the in vitro culture of wheat haploid induced by wheat $\times$ maize hybridization. Journal of Triticeae Crops, 28 (1), 1-5.

Gu, J., Liu, W., Li S., Tian, Y., Yang, H., Dan, Q. and Yang, M. (2006) A preliminary study on the application of wheat $\times$ maize to induce wheat haploid under natural conditions in Kunming. Journal of Triticeae Crops, 26 (4), 23-26.

Gu, J., Tian Y., Li, S., Liu, W., Yang, H. and Yang, M. (2005) Effects of wheat spike position and development progress on the induction rate of wheat $\times$ maize haploid embryos. Journal of Triticeae Crops, 25 (1), 30-32.

Hussain, B., Khan, M. A., Qurban, A. and Shaukat, S. (2012) Double haploid production in wheat through microspore culture and wheat $\mathrm{x}$ maize crossing system: An Overview. IJAVMS, 6 (5), 332-344.

Inagaki, M. (1997) Use of pollen storage and detached tiller culture in wheat polyploidy production through wide cross. Cereal Res. Comm., 25, 7-13.

Inagaki, M. and Tahir, M. (1992) Production of haploid wheat through intergeneric crosses. Hereditas, 116 , 117-120.

Kisan, N. S. (1993) Production of haploid wheat plants from wheat $\times$ maize crosses. Plant Breeding, 110, 96-102.

Laurie, D. A. (1989) Factors affecting fertilization frequency in crosses of Triticum aestivum cv. "highbury" $\times$ Zea mays cv "Seneca60". Plant breeding, 103, 133-140.

Laurie, D. A. and Bennett, M. D. (1986) Wheat $\times$ maize hybridization. Can. J. Genet. Cytol., 28, 313-316.

Laurie, D. A. and Bennett, M. D. (1988) The production of haploid wheat plants from wheat $\times$ maize crosses. Theor. Appl. Genet., 76, 393-397.

Laurie, D. A. and Reymondie, S. (1991) High frequencies of fertilization and haploid seedling production in crosss between commercial hexploid wheat varieties and maize. Plant Breeding, 106, 182-189. 
Lefebvre, D. and Devaux, P. (1996) Doubled haploids of wheat from wheat $\times$ maize Crosses: Genotypic influence, fertility and inheritance of the 1B-1RS chromosome. Theor. Appl. Genet., 93, 1267-1273.

Li, D. and Dai, W. (2000) Study on the application of dyeing method in wheat breeding. Journal of Agricultural Biotechnology, 8 (1), 17-21.

Maluszynski, M., Kasha, K. J., Forster, B. P. and Szarejko, I. (2003) Doubled haploid production in crop plants: A manual. Kluwer Academic Publ, Dordrecht, Boston, London, 1-20.

Sun, J., Liu, H., Lu, T., Wang, X. and Ren, Z. (1992) the production of wheat plants via wheat $\mathrm{x}$ maize hybridization. Acta Botanica, 34, 817-821.

Vinesh, V., Bains, N.S., Nanda, G.S., Gosal, S.S. and Singh, K. (1999) Maize genotypes show striking differences for induction and regeneration of haploid wheat embryos in wheat $\times$ maize system. Crop Sci., 39, 1722-1727.

Wang, G. (1998) Study on the haploid frequency produced by hybridization of wheat and maize. Journal of Triticeae Crops, 18 (6), 12-14.

Wang, Z. and Zhang, Y. (2001) The new lines of waxy wheat were accelerated by haploid breeding technique. North China Agricultural Journal, 16 (1), 1-6.
Wang, Z., Fan, Z., Zhang, Y., Li, J., Gao, X., and Wang, Z. X. (2016) Analysis of influencing factors on embryo rate of haploid embryos in spring wheat. Xinjiang Agricultural Science, 53(8), 1397-1403.

Wiśniewska, H., Majka, M., Kwiatek, M., Gawłowska, M., Surma, M., Adamski, T., Kaczmarek, Z., Drzazga, T., Lugowska, B., Korbas, M. and Belter, J. (2019) Production of wheat-doubled haploids resistant to eyespot supported by marker-assisted selection. Electronic Journal of Biotechnology 37, $11-17$.

Zenkteler, M. and Nitzsche, W. (1984) Wide hybridization experiments in cereals. Theor. Appl. Genet., 68, 311-315.

Zhang, M. (2010) Study on the yield of haploid embryos induced by hybridization between wheat and maize. Heilongjiang Agricultural Sciences, 5, 23-24.

Zhang, X., Gao, G., Shi, S., Bai, G. and Gu, L. (2007) Effect of 2,4-D on the rate of maize haploid induced wheat haploid embryo. Journal of Gansu Agricultural University, 42 (3), 44-46.

(Received:15/1/2019; accepted:3/ 2 /2019) 


\title{
تأثير بعض التراكيب الوراثية من الذرة علي معدل انتاج أجنة القمح الاحادية في تقنية ألتهجين بين القمح و الذرة
}

دنج منج لينج', سيدهم عبد الخالق', ', , لي هونج شنج', يانج ميجن', لي شاو زينج', جو جيان', زاو

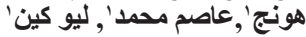

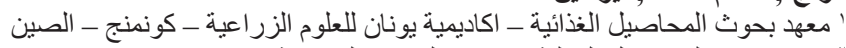

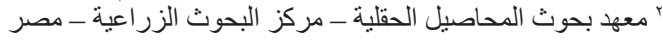

\begin{abstract}
أجريت هذه الدراسة في محطة بحوث سونمنج، كونمنج ، و لالية يونان ، الصين بهدف دراسة تأثير ثمانية تر اكيب

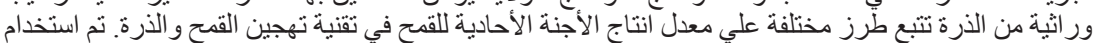

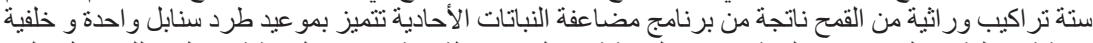

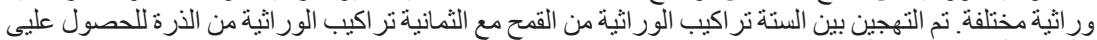

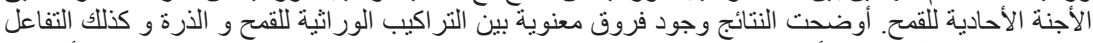

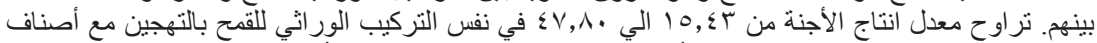

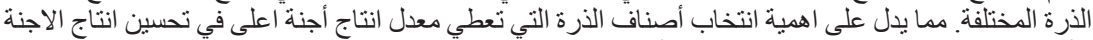

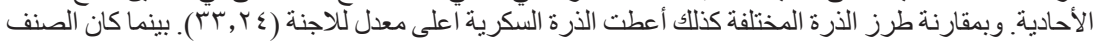

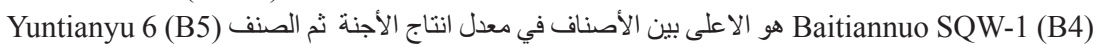

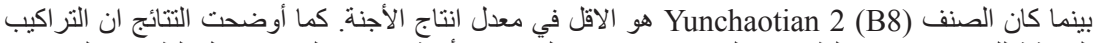

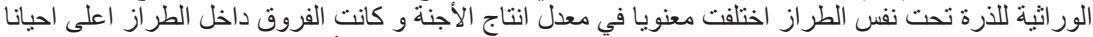

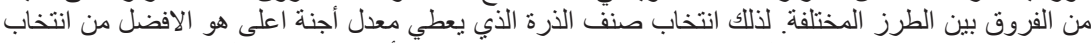

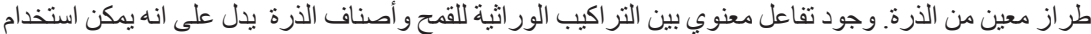

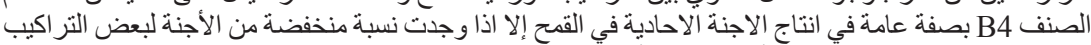
الور اثثية من القمح فيمكن استخدام أصناف ذرة أخرى.
\end{abstract}

